\title{
O Paraná na dinâmica da renda do sistema inter-regional
}

\section{Sul-Restante do Brasil}

\author{
Antonio Carlos Moretto \\ Rossana Lott Rodrigues* \\ Umberto Antonio Sesso Filho** \\ Katy Maia ${ }^{* * * *}$
}

RESUMO - Os anos 90 trouxeram a necessidade de reestruturação de amplos setores produtivos da economia brasileira. Em nível regional as respostas às mudanças ocorridas no período, embora devam caminhar na mesma direção, certamente apresentam particularidades em função de suas próprias características. Analisar parte dessas mudanças no sistema interregional Sul- Restante do Brasil usando a matriz de insumo-produto de 1999 foi o objetivo geral desse artigo. Especificamente pretendeu-se avaliar a dinâmica da renda, via efeito tranbordamento do multiplicador de renda. Os principais resultados mostraram: a) maior integração dos estados do Sul com o Restante do Brasil do que dentro da própria região; b) a importância do setor 17 - indústria alimentar - dentro da estrutura produtiva da Região Sul, caracterizando-se como segmento mais dependente do Restante do Brasil no que se refere à geração de renda; c) o Paraná como importante apropriador de renda dos dois estados do Sul e do Restante do Brasil; d) Santa Catarina como importante comprador e absorvedor de maior parte do comércio intra-regional, colaborando mais intensivamente para a geração de renda nas outras regiões estudas.

Palavras-chave: Sistema inter-regional. Insumo-produto. Renda. Região Sul. Paraná.

\section{INTRODUÇÃO}

Os anos 90 trouxeram a necessidade de reestruturação de amplos setores produtivos da economia brasileira, obrigados a enfrentar concorrentes globais, num cenário de abertura comercial irreversível dentro da atual política comercial e das condições internacionais vigentes.

Assim, a economia brasileira vivenciou um período de rápidas e profundas mudanças estruturais durante a década de 1990, conjugando o processo de abertura comercial, a privatização de setores importantes (a exemplo dos setores elétrico e de telecomunicações),

\footnotetext{
* Professor do Departamento de Economia da Universidade Estadual de Londrina. Endereço eletrônico: acmoretto@uel.br.

** Professora do Departamento de Economia da Universidade Estadual de Londrina. Endereço eletrônico: rlott@uel.br.

*** Professor do Departamento de Economia da Universidade Estadual de Londrina. Endereço eletrônico: umasesso@uel.br.

**** Professora do Departamento de Economia da Universidade Estadual de Londrina Endereço eletrônico: katymaia@uel.br.
} 
a liberalização dos fluxos de capitais com o programa de estabilização, alicerçado em uma âncora cambial, com reflexos importantes sobre toda a economia.

Considerando a variação da taxa de câmbio efetiva real e o saldo da balança comercial do Brasil, pode-se dividir a década de 1990 em três períodos.

No primeiro, entre os anos de 1990/94, ocorreu a primeira fase da abertura comercial, marcada pelo impacto das importações sobre uma economia que permaneceu fechada por longo período. O segundo período, 1995/98, teve como características principais o regime de câmbio fixo e a valorização da moeda nacional, com déficits da balança comercial. No terceiro, 1999-2000, ocorre a maxidesvalorização da moeda nacional e o regime é modificado para câmbio flexível, com melhora da balança comercial (BAER, 1996 e GREMAUD et al, 1996).

No período compreendido entre 1990 e setembro de 1993, com a implementação e consolidação do programa de redução das barreiras tarifárias e eliminação das barreiras não tarifárias no governo Collor, a indústria doméstica passou a competir com os produtos importados e a produção industrial brasileira diminuiu em valor 12,2 pontos percentuais (KUME et al, 2003).

Para Ramos e Reis (1998) a característica marcante do ajustamento da economia brasileira à abertura comercial no início da década de 90 está relacionada ao nível de emprego do setor industrial. De fato, parece inegável que a reestruturação organizacional e produtiva das empresas industriais no início da década de 90 passou pelo corte de pessoal, como forma de reduzir custos.

Os ajustes substanciais promovidos pela indústria brasileira nos anos 90 não se detiveram à produção e ao emprego ${ }^{36}$. $\mathrm{A}_{\text {qualificação }}{ }^{37}$, a produtividade $^{38}$, e os salários $^{39}$ também se adequaram em resposta à abertura comercial no início da década. Tudo leva a crer que esses fatos decorrem dos efeitos do processo de reestruturação produtiva da indústria nacional, baseado, fundamentalmente, na implantação de modernas técnicas de gestão e controle da qualidade e da adoção de tecnologia com viés para o trabalho qualificado.

Outra questão que emerge desse processo e preocupa os pesquisadores é o movimento de concentração, tanto no campo produtivo quanto no patrimonial (fusões,

36 Ver Sabóia (2001) para uma visão sobre desconcentração da produção e do emprego industrial na década de 90.

37 Ver Arbache (2001) e Menezes-Filho e Rodrigues Júnior (2001), entre outros, para a complementaridade entre tecnologia e trabalho qualificado.

38 Ver Chamon (1998), Cacciamali e Bezerra (1997), Rossi Júnior e Ferreira (1999), Considera e Silva (1993) e Silva et al. (1993), dente outros.

${ }^{39}$ Ver Chamon (1998) e Campos (2004).

66 
aquisições, entrada de grandes empresas oligopolistas no mercado, ampliação de escalas de produção, etc.), envolvendo, inclusive, uma dimensão regional, com regiões elevando sua já expressiva participação no PIB nacional e/ou estadual (VASCONCELOS e CASTRO, 1999).

A participação no PIB e na balança comercial são duas variáveis que mostram as diferenças regionais em termos de comportamento econômico recente. O produto ou renda e sua dinâmica inter-regional podem revelar a maior dependência de uma região relativamente à outra e oferecer informações importantes para o planejamento e ações de políticas econômicas e sociais públicas setoriais e regionais desenvolvimentistas e para a tomada de decisão dos agentes privados.

Assim, o objetivo geral desta pesquisa foi verificar como o cenário dos anos 90 e seus desdobramentos impactaram os diferentes setores da estrutura produtiva dos três estados do Sul, as relações destes estados entre si e suas relações com o restante do Brasil no que se refere à geração de renda em 1999. Especificamente, pretendeu-se calcular o efeito transbordamento dos multiplicadores de renda para o sistema inter-regional Restante do Brasil, Paraná, Santa Catarina e Rio Grande do Sul.

Além dessa introdução, o artigo se estrutura em mais três partes. A segunda descreve os métodos de análise usados, a terceira discute os resultados enquanto a quarta apresenta as contribuições esperadas.

\section{PROCEDIMENTOS METODOLÓGICOS}

\subsection{FONTE DOS DADOS}

Para a realização deste estudo foi utilizada a matriz insumo-produto do Brasil para o ano de 1999, subdividida nas seis grandes regiões, estimada por Guilhoto et al (2002). Por meio do método do quociente locacional, foi estimado o sistema inter-regional com quatro regiões, Restante do Brasil - Paraná - Santa Catarina - Rio Grande do Sul, e 26 setores, utilizando dados disponibilizados pelo IBGE (2003).

\subsection{MÉTODOS DE ANÁLISE}

\subsubsection{Multiplicador e transbordamento do efeito multiplicador de renda ${ }^{40}$}

Os multiplicadores complementam a análise da importância de determinado setor na economia, na medida em que é instrumento útil na verificação de impactos sobre determinado sistema econômico resultante de choques nos elementos exógenos, no curto ou

40 Nesta seção é descrito apenas o multiplicador simples. Para outros tipos de multiplicadores ver Miller e Blair (1985). 
longo prazo. Segundo Miller e Blair (1985), o uso do multiplicador permite verificar os efeitos de políticas públicas sobre a produção total da economia ou sobre outras variáveis como o nível de emprego e a renda.

Assim, dado que $X=(I-A)^{-1}$ é a matriz inversa de Leontief, $l_{i j}$ seus elementos da linha $i$ e coluna $j$, e $n$ o número de setores, o multiplicador setorial de renda $\left(M R_{j}\right)$ permite determinar o impacto de variações na demanda final sobre a renda recebida pelas famílias. $\mathrm{O}$ multiplicador de renda simples para o setor $j$ mostra a nova renda gerada em todos os setores da economia resultante do aumento de uma unidade monetária de demanda final pelo produto do setor $j$. Assim, o multiplicador de renda simples pode ser expresso da seguinte forma:

$$
M R_{j}=\sum_{\mathrm{i}=1}^{\mathrm{n}} a_{\mathrm{n}+1, \mathrm{i}} l_{i j}
$$

em que $a_{n+1, i}$ é um elemento da linha correspondente ao coeficiente da renda das famílias.

A partir do multiplicador de renda pode-se calcular o transbordamento do seu efeito para dado setor de uma região em relação à outra, o qual pode ser apresentado tanto em termos absolutos quanto em valores percentuais. Enquanto o somatório dos elementos da matriz inversa referente à própria região constitui o efeito multiplicador interno, o somatório dos elementos da coluna $j$ referentes ao fluxo inter-regional de bens e serviços é o valor do transbordamento do efeito multiplicador (efeito multiplicador fora da região de origem do setor). Como se pode observar, na equação (16), os elementos $l_{i j}$ da matriz $L^{L L}$, somados em colunas, são o efeito multiplicador dentro da região L, enquanto os somatórios das colunas da matriz $L^{M L}$ são transbordamentos do efeito multiplicador dos setores da região L para a região M.

No caso deste estudo, o efeito transbordamento mostra como o aumento da renda setorial em dada região impacta a renda dos setores de outra região. Como os cálculos foram realizados para 4 regiões, Restante do Brasil - Paraná - Santa Catarina - Rio Grande do Sul, e 26 setores, $i=j=104$.

\section{RESULTADOS E DISCUSSÃO}

A Tabela 1 apresenta os resultados da decomposição da geração do valor adicionado dos setores do Restante do Brasil sobre os setores do Paraná, Santa Catarina e Rio Grande do Sul quando se imprime uma variação de $\mathrm{R} \$ 1$ mil na demanda final em 1999. Observou-se pequeno efeito transbordamento de renda para os estados da Região Sul, variando, em média, 
de 6 a 12 reais para a geração média de $\mathrm{R} \$ 821,00$ por mil reais de variação da demanda final em cada setor.

O Paraná se destacou com, em média, $\mathrm{R} \$ 12,00$ para cada mil reais de variação da demanda final dos setores do Restante do Brasil. Os maiores valores encontrados se referiram aos setores do Restante do Brasil que dependeram dos setores 17 - Indústria alimentar, 13 Artigos plásticos, 10 - Indústria da borracha e 9 - Celulose, Papel e Gráfica do Paraná.

É interessante notar que, para os três estados do Sul, o setor 17 - Indústria alimentar foi o mais impactado em termos de valor adicionado. Isto mostra a importância da indústria alimentar dentro da estrutura produtiva da Região Sul, caracterizando-se como segmento mais dependente do Restante do Brasil no que se refere à geração de renda.

TABELA 1 - DECOMPOSIÇÃO DA GERAÇÃO VALOR ADICIONADO A PREÇO BÁSICO PARA A VARIAÇÃO DE R\$ 1 MIL DA DEMANDA FINAL, POR SETOR, RESTANTE DO BRASIL - 1999. (R\$DE 1999).

\begin{tabular}{|c|c|c|c|c|c|}
\hline \multirow[b]{2}{*}{ Setores } & \multicolumn{5}{|c|}{ Restante do Brasil } \\
\hline & $\begin{array}{l}\text { Restante } \\
\text { do Brasil }\end{array}$ & Paraná & $\begin{array}{c}\text { Santa } \\
\text { Catarina }\end{array}$ & $\begin{array}{c}\text { Rio Grande } \\
\text { do Sul }\end{array}$ & Total \\
\hline 1 Agropecuária & 866 & 11 & 4 & 9 & 889 \\
\hline 2 Extrativa Mineral & 857 & 8 & 5 & 8 & 878 \\
\hline 3 Minerais não Metálicos & 791 & 8 & 4 & 7 & 809 \\
\hline 4 Metalurgia & 742 & 10 & 5 & 9 & 766 \\
\hline 5 Mecânica & 819 & 10 & 6 & 9 & 844 \\
\hline 6 Material Elétrico e Eletrônico & 673 & 16 & 10 & 14 & 713 \\
\hline 7 Material de Transportes & 642 & 15 & 9 & 14 & 680 \\
\hline 8 Madeira e Mobiliário & 809 & 15 & 7 & 12 & 843 \\
\hline 9 Celulose, Papel e Gráfica. & 737 & 21 & 10 & 16 & 785 \\
\hline 10 Indústria da Borracha & 671 & 28 & 12 & 21 & 732 \\
\hline 11 Química & 759 & 11 & 4 & 7 & 781 \\
\hline 12 Farmácia e Veterinária & 774 & 23 & 11 & 17 & 825 \\
\hline 13 Artigos Plásticos & 706 & 30 & 9 & 22 & 767 \\
\hline 14 Indústria Têxtil & 691 & 13 & 7 & 13 & 724 \\
\hline 15 Artigos do Vestuário & 750 & 9 & 9 & 8 & 775 \\
\hline 16 Fabricação de Calçados & 759 & 10 & 6 & 12 & 787 \\
\hline 17 Indústria alimentar & 770 & 32 & 14 & 24 & 840 \\
\hline 18 Indústrias Diversas & 777 & 7 & 4 & 6 & 794 \\
\hline 19 Serviços indust. de utilid. pub. & 867 & 5 & 2 & 4 & 879 \\
\hline 20 Construção Civil & 842 & 7 & 6 & 6 & 861 \\
\hline 21 Comércio & 857 & 9 & 3 & 6 & 875 \\
\hline 22 Transporte & 767 & 11 & 4 & 9 & 790 \\
\hline 23 Comunicações & 921 & 3 & 2 & 3 & 928 \\
\hline 24 Instituições Financeiras & 922 & 4 & 2 & 3 & 930 \\
\hline 25 Administração Pública & 914 & 4 & 2 & 4 & 923 \\
\hline 26 Outros Serviços & 909 & 6 & 3 & 5 & 923 \\
\hline Médias & 792 & 12 & 6 & 10 & 821 \\
\hline
\end{tabular}


A Tabela 2 mostra a decomposição da geração do valor adicionado dos setores do estado do Paraná. Os resultados mostraram maior interação deste com o Restante do Brasil

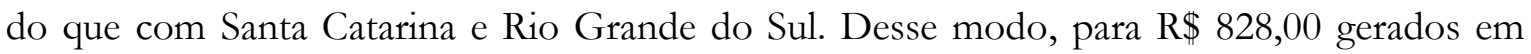
termos de renda, $R$ \$ 149,00 transbordaram para o Restante do Brasil, enquanto apenas $R \$$ 11,00 e R\$ 10,00 ficaram em Santa Catarina e Rio Grande do Sul, respectivamente. Os maiores valores de transbordamento para o Restante do Brasil ocorreram para 8 - Madeira e mobiliário, 7 - Material de transportes e 15 - Artigos do vestuário.

A decomposição da geração do valor adicionado dos setores do estado de Santa Catarina está apresentada na Tabela 3. Como observado para o Paraná, verificou-se maior interação deste Estado com o Restante do Brasil do que com os outros dois Estados da Região Sul. Assim, dos R \$ 873,00 gerados em termos de renda, R \$ 156,00 transbordaram para o Restante do Brasil, enquanto apenas $\mathrm{R} \$ 24,00$ e $\mathrm{R}$ \$ 16,00 ficaram em Paraná e Rio Grande do Sul, respectivamente. Os maiores valores de transbordamento para o Restante do Brasil ocorreram para os setores 13 - Artigos Plásticos, 14 - Indústria Têxtil e 22 - Transportes.

TABELA 2 - DECOMPOSIÇÃO DA GERAÇÃO DE VALOR ADICIONADO A PREÇO BÁSICO PARA A VARIAÇÃO DE R\$ 1 MIL DA DEMANDA FINAL, POR SETOR, PARANÁ - 1999. (R\$ DE 1999)

\begin{tabular}{ll|r|r|rrr}
\hline \multirow{2}{*}{ Setores } & \multicolumn{6}{c}{ Paraná } \\
\cline { 2 - 7 } & $\begin{array}{c}\text { Restante } \\
\text { do Brasil }\end{array}$ & Paraná & $\begin{array}{c}\text { Santa } \\
\text { Catarina }\end{array}$ & $\begin{array}{c}\text { Rio Grande } \\
\text { do Sul }\end{array}$ & Total \\
\hline 1 & 133 & 752 & 6 & 8 & 900 \\
2 & Agropecuária & 35 & 865 & 2 & 2 & 905 \\
3 & Mintrativa Mineral não Metálicos & 157 & 620 & 8 & 8 & 794 \\
4 & Metalurgia & 112 & 661 & 5 & 5 & 783 \\
5 & Mecânica & 211 & 592 & 10 & 12 & 825 \\
6 & Material Elétrico e Eletrônico & 186 & 552 & 7 & 9 & 755 \\
7 & Material de Transportes & 317 & 347 & 14 & 23 & 700 \\
8 & Madeira e Mobiliário & 332 & 473 & 19 & 26 & 850 \\
9 & Celulose, Papel e Gráfica. & 240 & 500 & 28 & 24 & 792 \\
10 & Indústria da Borracha & 98 & 637 & 6 & 6 & 748 \\
11 & Química & 245 & 525 & 10 & 10 & 789 \\
12 & Farmácia e Veterinária & 89 & 723 & 6 & 6 & 824 \\
13 & Artigos Plásticos & 125 & 625 & 8 & 8 & 766 \\
14 & Indústria Têxtil & 79 & 582 & 6 & 5 & 672 \\
15 & Artigos do Vestuário & 307 & 394 & 40 & 11 & 751 \\
16 & Fabricação de Calçados & 98 & 660 & 8 & 8 & 774 \\
17 & Indústria alimentar & 203 & 610 & 17 & 17 & 847 \\
18 & Indústrias Diversas & 277 & 471 & 23 & 20 & 792 \\
19 & Serviços indust. de utilid. pub. & 66 & 839 & 7 & 7 & 919 \\
20 & Construção Civil & 122 & 761 & 17 & 8 & 909 \\
21 & Comércio & 142 & 708 & 12 & 11 & 873 \\
22 & Transporte & 158 & 629 & 10 & 12 & 809
\end{tabular}


23 Comunicações

24 Instituições Financeiras

25 Administração Pública

26 Outros Serviços

Médias

FONTE: Cálculos dos autores.

Finalmente, a Tabela 4 apresenta a decomposição da geração do valor adicionado dos setores do Rio Grande do Sul, evidenciando a maior interação deste Estado com o Restante do Brasil. Dos $\mathrm{R} \$ \mathbf{8 5 6 , 0 0}$ gerados em termos de renda, $\mathrm{R} \$ 109,00$ transbordaram para o Restante do Brasil, enquanto apenas $\mathrm{R} \$ 12,00$ e $\mathrm{R} \$$ 7,00 ficaram no Paraná e Santa Catarina, respectivamente. Os maiores valores de transbordamento para o Restante do Brasil ocorreram para os setores 10-Indústria da Borracha, 17-Indústria Alimentar e 22-Transporte juntos e 16-Fabricação de Calçados.

Desse modo, os resultados mostraram que, enquanto o Paraná é um importante fornecedor de bens e serviços e de empregos para os outros dois Estados da Região Sul e para o Restante do Brasil, se apropriando de parcela da renda que poderia ficar dentro destas economias, Santa Catarina, por apresenatar um parque industrial ainda em formação, relativamente ao Paraná e o Rio Grande do Sul, se constitui num importante comprador e absorvedor de maior parte do comércio intra-regional para alimentar seu processo produtivo, colaborando mais intensivamente para a geração de renda nestas regiões.

TABELA 3 - DECOMPOSIÇÃO DA GERAÇÃO DE VALOR ADICIONADO A PREÇO BÁSICO PARA A VARIAÇÃO DE R\$ 1 MIL DA DEMANDA FINAL, POR SETOR, SANTA CATARINA 1999. (R\$DE 1999)

\begin{tabular}{ll|r|rrrrr}
\hline \multirow{2}{*}{ Setores } & \multicolumn{5}{|c}{ Santa Catarina } \\
\cline { 2 - 6 } & $\begin{array}{c}\text { Restante } \\
\text { do Brasil }\end{array}$ & Paraná & $\begin{array}{c}\text { Santa } \\
\text { Catarina }\end{array}$ & $\begin{array}{c}\text { Rio Grande } \\
\text { do Sul }\end{array}$ & Total \\
\hline 1 & Agropecuária & 128 & 15 & 771 & 12 & 925 \\
2 & Extrativa Mineral & 101 & 17 & 753 & 9 & 880 \\
3 & Minerais não Metálicos & 201 & 31 & 609 & 18 & 859 \\
4 & Metalurgia & 136 & 23 & 692 & 12 & 863 \\
5 & Mecânica & 174 & 15 & 694 & 14 & 896 \\
6 & Material Elétrico e Eletrônico & 158 & 25 & 640 & 24 & 846 \\
7 & Material de Transportes & 146 & 20 & 634 & 13 & 813 \\
8 & Madeira e Mobiliário & 235 & 32 & 598 & 26 & 891 \\
9 & Celulose, Papel e Gráfica. & 185 & 38 & 604 & 26 & 853 \\
10 & Indústria da Borracha & 201 & 43 & 552 & 30 & 825 \\
11 & Química & 154 & 22 & 679 & 13 & 868 \\
12 & Farmácia e Veterinária & 92 & 13 & 786 & 8 & 899 \\
13 & Artigos Plásticos & 321 & 31 & 464 & 28 & 844 \\
14 & Indústria Têxtil & 280 & 36 & 445 & 29 & 790 \\
15 & Artigos do Vestuário & 232 & 43 & 520 & 19 & 814 \\
16 & Fabricação de Calçados & 114 & 19 & 706 & 12 & 852
\end{tabular}




\begin{tabular}{|c|c|c|c|c|c|}
\hline 17 Indústria alimentar & 138 & 22 & 714 & 16 & 891 \\
\hline 18 Indústrias Diversas & 233 & 34 & 566 & 25 & 859 \\
\hline 19 Serviços indust. de utilid. pub. & 110 & 45 & 697 & 18 & 869 \\
\hline 20 Construção Civil & 99 & 16 & 763 & 10 & 887 \\
\hline 21 Comércio & 208 & 32 & 632 & 21 & 892 \\
\hline 22 Transporte & 256 & 33 & 515 & 23 & 828 \\
\hline 23 Comunicações & 62 & 12 & 807 & 9 & 890 \\
\hline 24 Instituições Financeiras & 19 & 4 & 935 & 2 & 960 \\
\hline 25 Administração Pública & 41 & 8 & 891 & 5 & 945 \\
\hline 26 Outros Serviços & 42 & 7 & 898 & 5 & 952 \\
\hline Médias & 156 & 24 & 676 & 16 & 873 \\
\hline
\end{tabular}

FONTE: Cálculos dos autores.

TABELA 4 - DECOMPOSIÇÃO DA GERAÇÃO VALOR ADICIONADO A PREÇO BÁSICO PARA A VARIAÇÃO DE R \$ 1 MIL DA DEMANDA FINAL, POR SETOR, RIO GRANDE DO SUL - 1999. (R\$DE 1999)

\begin{tabular}{ll|r|r|rrr}
\hline \multirow{2}{*}{ Setores } & \multicolumn{5}{|c}{ Rio Grande do Sul } \\
\cline { 2 - 6 } & $\begin{array}{c}\text { Restante } \\
\text { do Brasil }\end{array}$ & Paraná & $\begin{array}{c}\text { Santa } \\
\text { Catarina }\end{array}$ & $\begin{array}{c}\text { Rio Grande } \\
\text { do Sul }\end{array}$ & Total \\
\hline 1 & Agropecuária & 99 & 15 & 6 & 789 & 908 \\
2 & Extrativa Mineral & 49 & 5 & 2 & 783 & 839 \\
3 & Minerais não Metálicos & 68 & 5 & 3 & 778 & 854 \\
4 & Metalurgia & 80 & 6 & 3 & 751 & 840 \\
5 & Mecânica & 113 & 10 & 10 & 774 & 908 \\
6 & Material Elétrico e Eletrônico & 42 & 4 & 2 & 781 & 829 \\
7 & Material de Transportes & 136 & 11 & 9 & 617 & 773 \\
8 & Madeira e Mobiliário & 99 & 12 & 7 & 777 & 895 \\
9 & Celulose, Papel e Gráfica. & 52 & 6 & 3 & 782 & 842 \\
10 & Indústria da Borracha & 219 & 28 & 15 & 532 & 793 \\
11 & Química & 224 & 21 & 6 & 589 & 840 \\
12 & Farmácia e Veterinária & 48 & 6 & 2 & 834 & 890 \\
13 & Artigos Plásticos & 76 & 7 & 3 & 748 & 835 \\
14 & Indústria Têxtil & 56 & 6 & 3 & 691 & 756 \\
15 & Artigos do Vestuário & 222 & 12 & 23 & 545 & 803 \\
16 & Fabricação de Calçados & 242 & 24 & 15 & 535 & 816 \\
17 & Indústria alimentar & 153 & 27 & 16 & 671 & 867 \\
18 & Indústrias Diversas & 233 & 18 & 13 & 570 & 834 \\
19 & Serviços indust. de utilidade pub. & 30 & 5 & 2 & 848 & 884 \\
20 & Construção Civil & 152 & 16 & 10 & 659 & 837 \\
21 & Comércio & 102 & 12 & 5 & 789 & 908 \\
22 & Transporte & 174 & 27 & 6 & 588 & 796 \\
23 & Comunicações & 59 & 5 & 4 & 814 & 883 \\
24 & Instituições Financeiras & 34 & 5 & 3 & 902 & 944 \\
25 & Administração Pública & 40 & 5 & 3 & 884 & 933 \\
26 & Outros Serviços & 33 & 4 & 2 & 910 & 949 \\
\hline & Médias & 109 & 12 & 7 & 729 & 856 \\
\hline
\end{tabular}

FONTE: Cálculos dos autores. 


\section{CONSIDERAÇÕES FINAIS}

A reestruturação produtiva pela qual passaram amplos setores da economia brasileira a partir dos anos 90, obrigados a enfrentar concorrentes globais, num cenário de abertura comercial irreversível dentro da atual política comercial e das condições internacionais vigentes, propiciaram respostas diferentes em nível regional.

Os aspectos particulares, oriundos de características próprias, contribuíram para que os três estados do Sul apresentassem comportamentos diferentes, seja no tocante à produção, ao emprego e à renda gerados nas suas inter-relações comerciais com o Restante do Brasil.

Como parte de um estudo maior desenvolvido pelos autores, este artigo teve como objetivo verificar os impactos da elevação da demanda final setorial na renda gerada e na sua transferência para as economias participantes do sistema inter-regional Sul - Restante do Brasil.

Assim, os principais resultados da distribuição do efeito multiplicador de renda mostraram que os maiores valores se concentraram no sentido Região Sul - Restante do Brasil, com destaque para o estado do Paraná, evidenciando maior integração dos estados do Sul com o Restante do Brasil do que dentro da própria região.

Considerando os três estados do Sul, o setor 17 - Indústria alimentar foi o mais impactado em termos de valor adicionado. Isto mostra a importância da indústria alimentar dentro da estrutura produtiva da Região Sul a qual se caracteriza como segmento mais dependente do Restante do Brasil no que se refere à geração de renda.

Considerando os três estados da Região Sul, observou-se maior transbordamento do multiplicador de renda no sentido Santa Catarina-Paraná e Rio Grande do Sul-Paraná, o que indica que o estado do Paraná é um importante fornecedor de bens e serviços e de empregos tanto aos outros dois estados do Sul quanto ao Restante do Brasil. Isto permite ao Paraná se apropriar de parcela da renda que poderia ficar dentro destas economias.

Por outro lado, cabe destacar, também, o transbordamento do multiplicador de renda no sentido Santa Catarina - Paraná e Santa Catarina - Rio Grande do Sul. Santa Catarina, por ter um parque industrial ainda em formação, comparativamente ao Paraná e ao Rio Grande do Sul, constitui-se em um importante comprador e absorvedor de maior parte do comércio intra-regional para alimentar seu processo produtivo, colaborando mais intensivamente para a geração de renda nestas regiões. 
É importante esclarecer que a menor ou maior dependência de uma economia em relação à outra, por si só, não é uma característica boa ou ruim. Estas relações que foram quantificadas, sinalizam as diferentes estruturas das economias em foco e se constituem em um conjunto de informações que poderá ser usado pelo governo, pelas empresas ou pelos setores como base para a adoção de políticas públicas ou privadas de desenvolvimento setorial ou regional.

Para futuros estudos, dando continuidade ao foco na Região Sul, sugere-se agregar os três estados na forma de um sistema inter-regional com duas regiões, buscando evidenciar, até que ponto, a união de Paraná, Santa Catarina e Rio Grande do Sul modifica as relações comerciais com o Restante do Brasil.

\section{REFERÊNCIAS}

ARBACHE, J. S. Trade liberalisation and labour market in developing countries: theory and evidence. University of Kent, Department of Economics Discussion Paper 01/12, jun. 2001.

BAER, WERNER. A Economia Brasileira. São Paulo: Nobel, 1996. 416 p.

CACCIAMALI, M. C.; BEZERRA, L. de L. Produtividade e emprego industrial no Brasil. Revista Brasileira de Economia, v. 51, n. 1, p. 77-91, jan./mar., 1997.

CAMPOS, M. de F. S. de S. Abertura comercial, comércio intra-indústria e desigualdade de rendimentos na indústria de transformação brasileira. Tese (Doutorado em Economia). PIMES/UFPE, Recife, 2004.

CHAMON, M. Rising wages and declining employment: the brazilian manufacturing sector in the 90s. Rio de Janeiro: IPEA, 1998, Texto para Discussão 552.

CONSIDERA, C. M.; SILVA, A. B. A produtividade da indústria brasileira. Rio de Janeiro: IPEA/DIPES, 1993 (Sumário Executivo 1).

FUNCEX. Fundação Centro de Estudos do Comércio Exterior. Disponível em $<$ http//www.funcex.com.br $>$. Acessado em 05 agosto 2005.

GREMAUD, A. P., VASCONCELOS, M. A. S. \& TONETO Jr., R. Economia Brasileira Contemporânea: para os cursos de economia e administração. São Paulo: Atlas, 1996.

GUILHOTO, J. J. M.; SESSO FILHO, U. A.; LOPES, R. L.; HILGEMBERG, C. M. A. T.; HILGEMBERG, E. M. Nota metodológica: construção da matriz de insumo-produto utilizando dados preliminares das Contas Nacionais. In: II ENCONTRO BRASILEIRO DE ESTUDOS REGIONAIS E URBANOS. Anais ... São Paulo, 25 e 26 de outubro, 2002. 1 Cd-ROM.

INSTITUTO BRASILEIRO DE GEOGRAFIA E ESTATÍSTICA. Contas Regionais do Brasil, 2000. Rio de Janeiro, 2003. 108p.

IPEA. Instituto de Pesquisa Econômica Aplicada. Disponível em $<$ http//www.ipeadata.gov.br>. Acessado em: 05 agosto 2005b. 
KUME, H.; PIANI, G.; SOUZA, C. F. B. de A política brasileira de importação no período 1987-1998: descrição e avaliação. In: CORSEUIL, C. H.; KUME, H. A abertura comercial brasileira nos anos 1990: impactos sobre emprego e salário. Rio de Janeiro: IPEA, p. 9-37, 2003.

MENEZES-FILHO, N. A.; RODRIGUES JÚNIOR, M. Abertura, tecnologia e qualificação: evidências para a manufatura brasileira. In: WORKSHOP LIBERALIZAÇÃO COMERCIAL IPEA/UnB/MTE, Anais... Brasília, abr. 2001.

MILLER, R. E.; BLAIR, P. D. Input-output analysis: foundations and extensions. Englewood Cliffs, New Jersey: Prentice-Hall, Inc., 1985. 464 p.

RAMOS, L; REIS, J. G. A. Emprego no Brasil nos anos 90. In: IPEA. A economia brasileira em perspectiva, v. 2, p. 501-531, 1998.

ROSSI JÚNIOR, J. L.; FERREIRA, P. C. Evolução da produtividade industrial brasileira e abertura comercial. Pesquisa e Planejamento Econômico, v. 29, n. 1, p. 1-36, 1999.

SABÓIA, J. A dinâmica da descentralização industrial no Brasil. Rio de Janeiro: UFRJ/Instituto de Economia (Texto para Discussão IE/UFRJ n. 452), 20

SILVA, A. et al. Retrospectiva da economia brasileira. Perspectivas da Economia Brasileira - 1994, cap. 1. Rio de Janeiro: IPEA, p. 13-41, 1993.

VASCONCELOS, J. R. de; CASTRO, D. Paraná: economia, finanças públicas e investimento nos anos 90. Brasília: IPEA. Texto para discussão n. 624, 1999. 
